\title{
Is additional balloon Kyphoplasty safe and effective for acute thoracolumbar burst fracture?
}

\author{
Ping-Jui Tsai ${ }^{1,2}$, Ming-Kai Hsieh ${ }^{1,2,3^{*}}$, Kuo-Feng Fan ${ }^{1,2}$, Lih-Huei Chen ${ }^{1,2}$, Chia-Wei Yu ${ }^{1,2}$, Po-Liang Lai ${ }^{1,2}$, \\ Chi-Chien Niu ${ }^{1,2}$, Tsung-Ting Tsai ${ }^{1,2}$ and Wen-Jer Chen ${ }^{1,2}$
}

\begin{abstract}
Background: Burst fracture is a common thoracolumbar injury that is treated using posterior pedicle instrumentation and fusion combined with transpedicular intracorporeal grafting after reduction. In this study, we compared the outcome of these two techniques by using radiologic imaging and functional outcome.

Methods: Sixty-one patients with acute thoracolumbar burst fracture were operated with kyphoplasty $(n=31)$ or vertebroplasty $(n=30)$ and retrospectively reviewed in our institution between 2011 and 2014. All 61 patients underwent surgery within 5 days after admission to the hospital and then followed-up for 12 to 24 months after surgery.
\end{abstract}

Results: Significant improvement was found in the anterior vertebral height ( $92 \pm 8.9 \%$ in the kyphoplasty group, 85 . $6 \pm 7.2 \%$ in the vertebroplasty group, $p<0.01)$ at 1 month post-operatively and $(89 \pm 7.9 \%$ in the kyphoplasty group, $78 \pm 6.9 \%$ in the vertebroplasty group, $p<0.01$ ) at the 24 -month follow-up. Significant improvement was also observed in the kyphotic angle $\left(1.2 \pm 0.5^{\circ}\right.$ in the kyphoplasty group, $10.5 \pm 1.2^{\circ}$ in the vertebroplasty group, $\left.p<0.01\right)$ at 1 month post-operatively and $\left(5.4 \pm 1.2^{\circ}\right.$ in the kyphoplasty group, $11.5 \pm 8.5^{\circ}$ in the vertebroplasty group, $\left.p<0.01\right)$ at the 24-month follow-up. Both operations led to significant improvement of the patients' pain and the Oswestry disability index $(p<0.01)$. Cement leakage was noted in $29 \%$ of patients after kyphoplasty and $77 \%$ of patients after vertebroplasty $(p<0.01)$. Only one implant failure $(3.3 \%)$, which required further surgical intervention, was reported in the vertebroplasty group.

Conclusions: Reduction with additional balloon at the fractured site is better than indirect reduction only by posterior instrumentation. The better reduction of kyphotic angle and the lower cement leakage rate in the kyphoplasty group indicate that additional balloon kyphoplasty is safe and effective for acute thoracolumbar burst fracture.

Keywords: Burst fracture, Vertebroplasty, Kyphoplasty, Calcium sulfate/phosphate cement, Acute thoracolumbar burst fracture

\section{Background}

Burst fracture is a common thoracolumbar injury that occurs because of failure of the anterior and middle columns due to axial loading [1]. When anterior vertebral body height loss exceeds $50 \%$, when the spinal canal is compromised by more than $50 \%$, or when angulation

\footnotetext{
*Correspondence: mk660628@gmail.com

'Department of Orthopedic Surgery, Chang Gung Memorial Hospital and Chang Gung University, Taoyuan, Taiwan

${ }^{2}$ Bone and Joint Research Center, Chang Gung Memorial Hospital, Linkou, Taiwan

Full list of author information is available at the end of the article
}

is greater than $20^{\circ}$ [1], surgical intervention should be considered. Recently, Thoracolumbar Injury Classification and Severity Score (TLICSS), which included fracture morphology, neurological injury and the integrity status of posterior ligamentous complex to determine stability and to decide operative or nonoperative treatment [2]. According to this classification, operative treatment is recommended for a score $\geq 5$ points, and conservative nonoperative treatment for a score $\leq 3$ points $[2,3]$.

Posterior pedicle instrumentation and fusion combined with transpedicular intracorporeal grafting after reduction 
is a well-known surgical technique $[4,5]$. Several different types of grafts exist, including autogenous bone grafts, allogenous bone grafts, and artificial bone grafts; these bone grafts are composed of polymethylmethacrylate (PMMA) or calcium sulfate, and calcium phosphate, among others [6-8]. Because of the complications at the donor site with autogenous bone grafts [9] and the risk of infection with allogenous bone grafts, artificial bone grafts are now more widely used. In addition, studies have shown that artificial bone grafts are as efficient as autogenous bone grafts [10].

Balloon kyphoplasty is a relatively effective technique to reduce the fracture site [11-14]. Reduction by balloon is speculated to effectively correct vertebral body height and angle. Another advantage of balloon kyphoplasty is decreased cement leakage, which is often a problem with vertebroplasty. Few researches [15] have compared the effects of balloon kyphoplasty with traditional vertebroplasty in acute thoracolumbar burst fracture. Our study aimed to compare the radiologic and functional outcomes of these two techniques.

\section{Methods}

Sixty-one patients with acute thoracolumbar burst fracture with or without neurologic deficit were treated with balloon kyphoplasty $(n=31)$ or vertebroplasty $(n=30)$ between 2011 and 2014 (Table 1). The Chang Gung Medical Foundation Institutional Review Board approved this study (103-3387B) and waived the requirement for informed consent because of the retrospective nature of the study. All the patients were treated with transpedicular intracorporeal grafting with calcium sulfate/phosphate cement and stabilization with pedicle-screw instrumentation. The

Table 1 Patient demographics data

\begin{tabular}{lllc}
\hline Characteristic & Kyphoplasty & Vertebroplasty & $p$ value \\
\hline Number of patients & 31 & 30 & 0.91 \\
Age & $35.5 \pm 6.5$ & $41.2 \pm 6.8$ & 0.814 \\
Gender: female (\%) & $14(54 \%)$ & $12(48 \%)$ & 0.258 \\
Location of fractured vertebrae & & \\
Thoracic (T8-T10) & 4 & 2 & 0.390 \\
T-L (T11-L1)aw & 21 & 19 & \\
Lumbar (L2-L3) & 6 & 9 & \\
Neurological status (ASIA ${ }^{+}$) & 1 & 6 & \\
A & 0 & 2 & 0.456 \\
B & 2 & 2 & \\
C & 2 & 1 & 0.551 \\
D & 26 & 19 & \\
E & $12.5 \pm 2.55$ & $13 \pm 3$ &
\end{tabular}

$\mathrm{ASIA}^{+}$: American Spine Injury Association impairment scale [17] results were compared in a retrospective, nonrandomized cohort study.

Operation was indicated when the patient had a thoracolumbar injury classification and severity score [16] greater than 5. Additional balloon kyphoplasty was favored in the presence of kyphotic vertebrae and disruption of the posterior vertebral cortex, where higher-viscosity cement can be injected. All 61 patients underwent surgery within 5 days after admission to the hospital and were followed up for at least 24 months after surgery. Each patient underwent neurologic assessment by using a rating scale based on the American Spine Injury Association (ASIA) impairment scale [17]. The treatment outcomes were assessed with special reference to the anterior vertebral height (AVH), kyphotic angle, degree of back pain (visual analog scale or VAS), the Oswestry disability index (ODI) at pre-operative and post-operative follow-up after $1,3,6,12$, and 24 months. Complications including cement leakage and implant failure were also assessed. Beginning on the day after surgery and continuing for 3 months, patients were encouraged to ambulation while wearing a Taylor's brace. Unrestricted activity was permitted after considering the individual patient's neurologic situation.

\section{Operative technique}

All operative procedures were performed with the patients under general anesthesia with endotracheal intubation. All patients were placed in a prone position on a radiolucent frame. Long or short constructs were planned and instrumented according to the level of the burst fracture. Long instrumentation (2 vertebrae above and 2 vertebrae below the fracture) was used for fractures between T11 and L2 (26 patients). Short instrumentation (One vertebra above and one vertebra below the fracture) was used if the fractured vertebra was located above T10 or below L3 (35 patients) (Table 2).

Pedicle screws (SmartLoc ${ }^{\circ}$ Spinal Fixation System, A-Spine Asia Co, Ltd., Taiwan) of the proper diameter were placed down into the pedicles of selected nonfractured vertebrae above and below the fractured vertebra using a standard posterior midline approach. Ligamentotaxis was achieved by proper longitudinal rod contouring [18] with distraction used along the entire area of instrumentation. Kyphoplasty was performed as follows: a cannula and an expander were inserted into the pedicle, and then a drill was inserted through the cannula. A balloon (Versys; SI Medical Co, Ltd., Korea) was inserted unilaterally into the fractured vertebral body and inflated slowly with initial bulk pressure [19]. Subsequently, the inflated balloon was deflated and withdrawn, then the intravertebral cavity was filled with calcium sulfate/phosphate cement (PRO-DENSE ${ }^{\bullet}$ Bone Graft Substitute, Wright Medical Technology, Arlington, TN, 
Table 2 Operative data

\begin{tabular}{llll}
\hline Operative Characteristic & Kyphoplasty & Vertebroplasty & $p$ value \\
\hline $\begin{array}{l}\text { Short (1 above and } 1 \text { below } \\
\text { fractured vertebra) }\end{array}$ & 19 & 16 & 0.312 \\
$\begin{array}{l}\text { Long (2 above and } 2 \text { below } \\
\text { fractured vertebra) }\end{array}$ & 12 & 14 & \\
Blood loss (ml) & $265 \pm 25$ & $215 \pm 85$ & 0.058 \\
Operative time (minutes) & $125 \pm 26$ & $115 \pm 14$ & 0.25 \\
Follow-up & $29.5 \pm 5.5$ & $28.5 \pm 4.5$ & 0.462 \\
Volume injected (ml) & $12 \pm 2.5$ & $6.5 \pm 1.5$ & $<0.01$ \\
\hline
\end{tabular}

USA) [20]. This calcium phosphate cement product in a radiopaque liquid that was injected anteriorly into the void produced by the balloon inflation (Figs. 1, 2). Vertebroplasty was performed with a cannula inserted into the fractured vertebra. Under the fluoroscopic monitoring, the calcium sulfate/phosphate cement was injected when the cannula reached the defect of the fractured vertebra (Figs. 3, 4). Decompressive laminectomy was performed in patients with neurological deficit. Posterior or posterolateral fusions were not performed in either group. Union was defined as continuous trabeculae of bridging anterior osteophytes on plain films with absence of halo signs of screws. Probable fusion was defined as unclear trabecular bone with no radiolucent screws. Radiolucent screws or osteolysis of augmented artificial bone was labeled as nonunion [21]. Complications included cement leakages, wound infection, cardiopulmonary embolism and nonunion were recorded and analyzed. Cement leakages were classified into three types: type $S$, via the segmental vein; type $B$, via the basivertebral vein; and type $\mathrm{C}$, through a cortical defect [22].

\section{Statistical analysis}

Data from both groups were analyzed with SPSS statistical software package (SPSS Inc., Chicago, IL, USA). Tests of hypotheses between both groups were conducted using a Student t-test for numerical data (including age, follow-up period, operation time, estimated blood loss, AVH, kyphotic angle, presence of back pain [VAS], and the ODI). $P$-values $<0.05$ were defined as statistically significant.

\section{Results}

No significant difference was observed in age, gender, location of fractured vertebrae, neurological status,

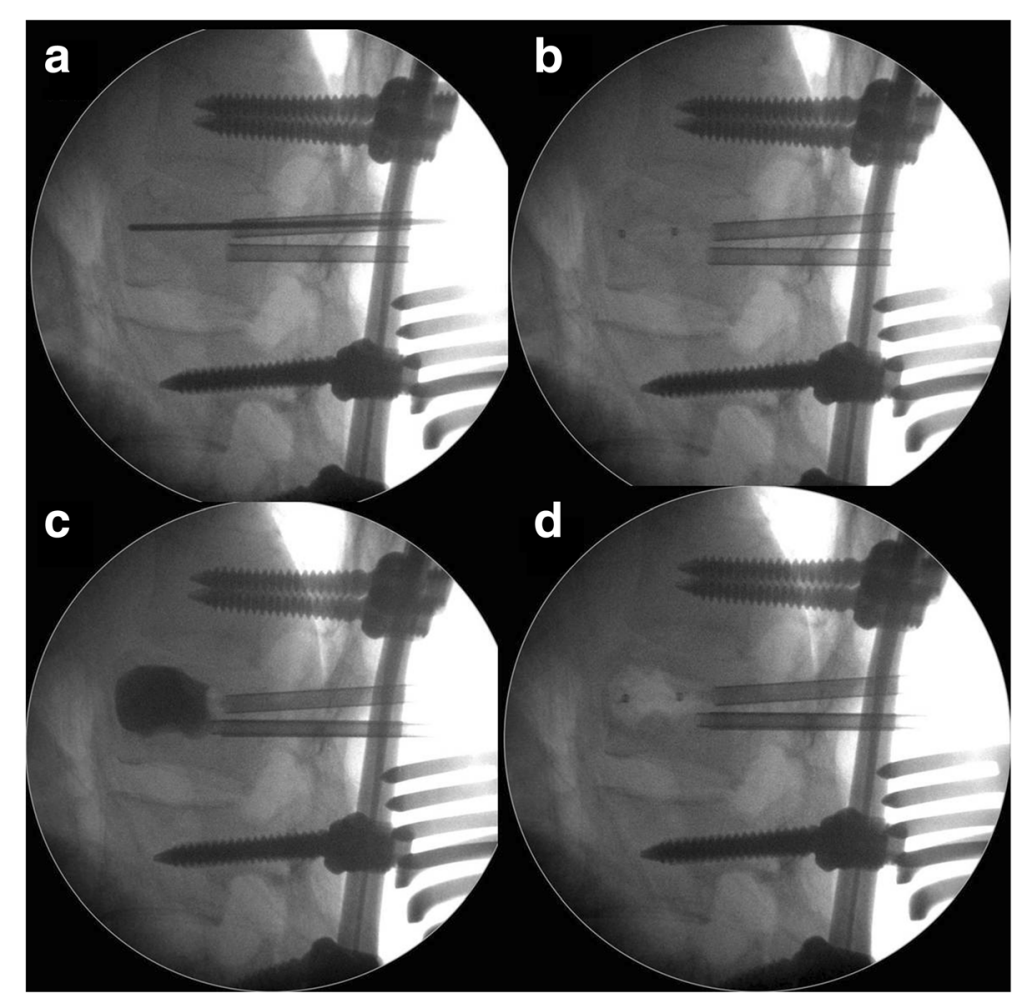

Fig. 1 Radiographic image of kyphoplasty technique. Kyphoplasty was performed using a cannula and an expander, which were inserted into the pedicle, as well as a drill, which was inserted through the cannula. A needle pipe and pin was placed parallel to the superior endplate in the lateral view (a). The balloon was slowly inflated with initial bulk pressure (b and $\mathbf{c}$ ). The volume of the balloon was carefully controlled to restore the fractured vertebra until adequate kyphotic angle reduction was obtained or the inflation pressure reached 220 psi [19]. The operator should record the amount of injected fluid to predict the cement volume. The balloon was deflated and withdrawn (d), and the created cavity was filled with cement [19] 


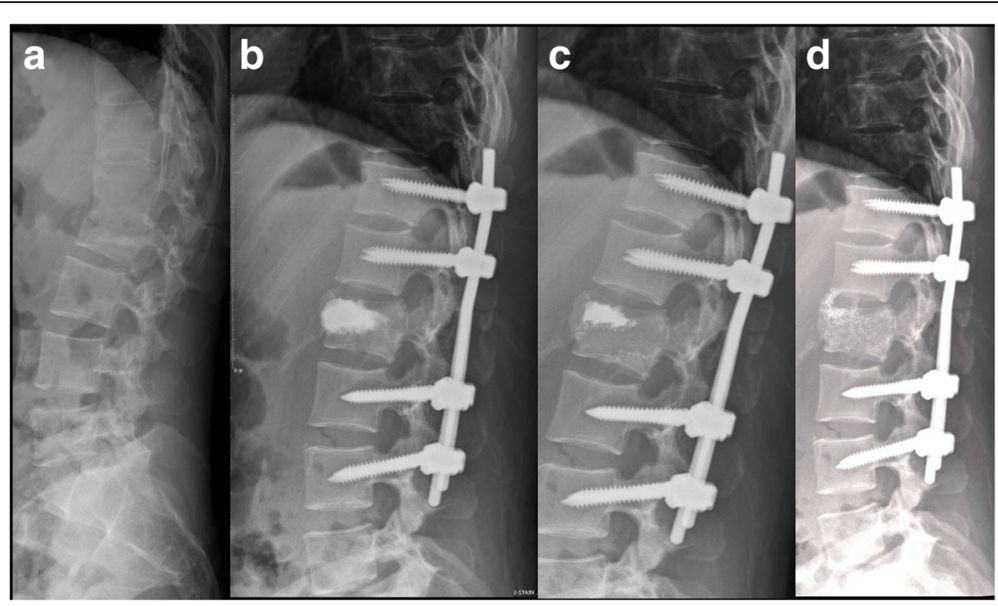

Fig. 2 Radiographic image of one patient who received kypoplasty and long instrumentation. a. Lateral roentgenogram of a 25-year-old female patient showing a burst fracture of $\mathrm{L} 2$; the kyphotic angle is $30^{\circ}$. b. Postoperative lateral $\mathrm{X}$-ray 3 days after surgery showing excellent restoration after kyphoplasty and long instrumentation; the kyphotic angle is $-6^{\circ}$. c. Intact implant and kyphotic angle is $-3^{\circ}$ three months after surgery. $\mathbf{d}$. Solid anterior fusion (continuous trabeculae of bridging anterior osteophytes without halo signs of screws) was achived and kyphotic angle was $0^{\circ} 12$ months after surgery

and hospital stay in both groups (Table 1). According to the ASIA neurologic grading scale, 7 patients had grade A, 2 patients had grade B, 4 patients had grade C, 3 patients had grade $\mathrm{D}$, and 45 patients had grade E. All 9 patients with incomplete neurologic deficit had at least 1 ASIA grade neurologic improvement at the 24-month follow-up.

The mean operative time in the kyphoplasty group was $125 \mathrm{~min}$ (range, 99-151 $\mathrm{min}$ ) and $115 \mathrm{~min}$ in the vertebroplasty group (range, 101-129 min) which was

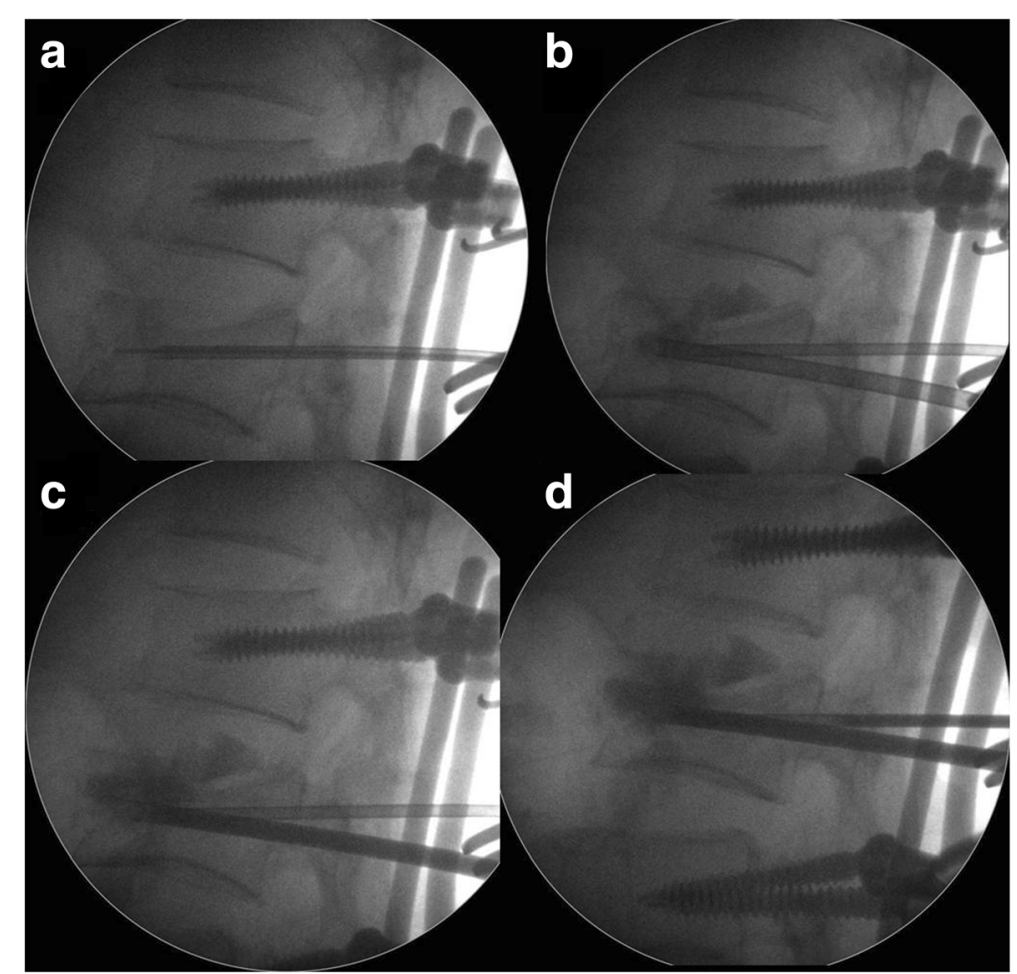

Fig. 3 Vertebroplasty technique and cement leakage. Vertebroplasty was performed by inserting a cannula into the fractured vertebra (a). Calcium sulfate/phosphate cement was injected when the cannula tip reached the defect of the fractured vertebra under fluoroscopic monitoring (b, $\mathbf{c}$ ). Intradiscal leakage and poor body reduction were noted during vertebroplasty (d) 


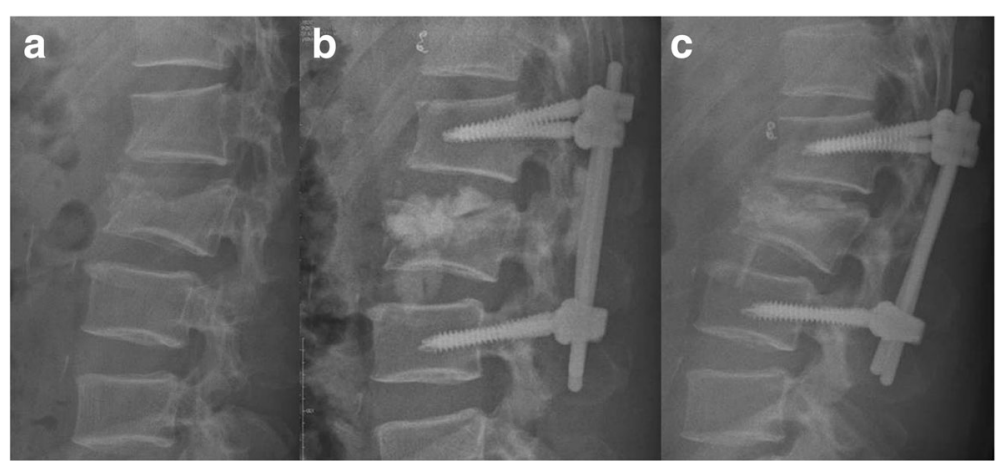

Fig. 4 Radiographic image of one patient who received vetebralplasty and short instrumentation. a. Lateral roentgenogram of a 35-year-old male patient showing a L3 burst fracture; the kyphotic angle is $20^{\circ}$. b. Postoperative lateral roentgenogram showing good reduction (the kyphotic angle is 0 degree) through vertebroplasty and short instrumentation with intradiscal and paraspinal leakages 3 days after surgery. c. The kyphotic angle is $-3^{\circ} 12$ months after surgery and solid anterior fusion (continuous trabeculae of bridging anterior osteophytes without halo signs of screws) was achived. But the kyphotic angle is 12 degree and the rod was bended 12 months after surgery

not statistically significant difference $(p=0.25)$. The total volume of blood loss was $265 \mathrm{ml}$ in the kyphoplasty group (range, $240-290 \mathrm{ml}$ ) and $215 \mathrm{ml}$ in the vertebroplasty group (range, 130-300); the difference was also not statistically significant $(p=0.058)$. All patients were observed in an average follow-up of 29 months (range, 24-36 months). The volume of cement injected in the kyphoplasty group was $12 \mathrm{ml}$ (range, $9.5-14.5 \mathrm{ml}$ ) and $6.5 \mathrm{ml}$ in the vertebroplasty group (range, $5-8 \mathrm{ml}$ ); the difference was statistically significant $(p<0.01)$ (Table 2 ).

Significant improvement in the AVH $(92 \pm 8.9 \%$ in the kyphoplasty group, $85.6 \pm 7.2 \%$ in the vertebroplasty group, $\mathrm{p}<0.01$ ) was found at 1 month post-operatively and $(89 \pm 7.9 \%$ in the kyphoplasty group, $78 \pm 6.9 \%$ in the vertebroplasty group, $\mathrm{p}<0.01$ ) at the 24 -month follow-up. The kyphotic angle between the two groups was also significant with $1.2 \pm 0.5^{\circ}$ in the kyphoplasty group and $10.5 \pm 1.2^{\circ}$ in the vertebroplasty group $(p<0.01)$ at 1 month post-operatively, and $5.4 \pm 1.2^{\circ}$ in the kyphoplasty group and $11.5 \pm 8.5^{\circ}$ in the vertebroplasty group $(p<0.01)$ at the 24-month follow-up (Fig. 5a, b). Both surgical procedures resulted in improvement of the patients' pain and the ODI without statistical significance between the two groups (Fig. 5).

\section{Complications.}

The three patterns in C-type leakage are paraspinal, intradiscal, and posterior. Cement leakage was observed in $29 \%$ of patients in the kyphoplasty group (including $6 \%$ leakages via the segmental vessels, $10 \%$ through a paraspinal cortical defect, and $13 \%$ through a intradiscal cortical defect) and in $77 \%$ of patients after vertebroplasty (including 3\% leakages via the basivertebral vein, $10 \%$ via segmental vein, $20 \%$ leakages through a paraspinal cortical defect, $30 \%$ through a intradiscal cortical defect, and 14\% through the posterior cortical wall) $(p<0.01)$ (Fig. 6). There is no intraoperative cardiogenic hypotension, pulmonary embolism, or deteriorated neurological deficit in the 32 patients (9 and 23 in the kyphoplasty and vertebroplasty groups, respectively) with cement leakage. Superficial wound infection or deep wound infection was not found in our series. At the final follow-up, 60 of the 61 patients exhibited union or probable union. Nonunion was only in one implant $(3.3 \%)$ in the vertebroplasty group, which required further surgical intervention. There is no adjacent vertebral fractures in the 2-year follow-up.

\section{Discussion}

In this study, long instrumentation were performed in T11L1 fractured vertebrae. 9 patients with T11-L1 fractured vertebrae in kyphoplasty group and 5 patients in vertebroplasty group were performed short instrumentation because of strong bone screw purchase. However, the results of many studies [10,23-25] showed that lack of anterior support may lead to a high percentage of early implant failure. A large cavity in fractured vertebrae is created during posterior instrumented construct after application of a distraction force, and thus may lead to reduction site collapse and worsened clinical outcomes. The materials used for anterior reconstruction includes autogenous and artificial bone grafts. The results of several studies have shown that artificial bone grafts produce similar success rates to autogenous bone grafts. In addition, the use of artificial bone grafts may lead to shorter operation time and less blood loss [10].

Many techniques have been used to establish anterior vertebral support. Vertebroplasty, which was first used in 1987 [26], became an efficient method for treating compression fractures [27]. Balloon-assisted kyphoplasty is a developed technique $[19,28,29]$ to restore the vertebral body height and to treat local kyphosis which also contributes to anterior column stability. In the 

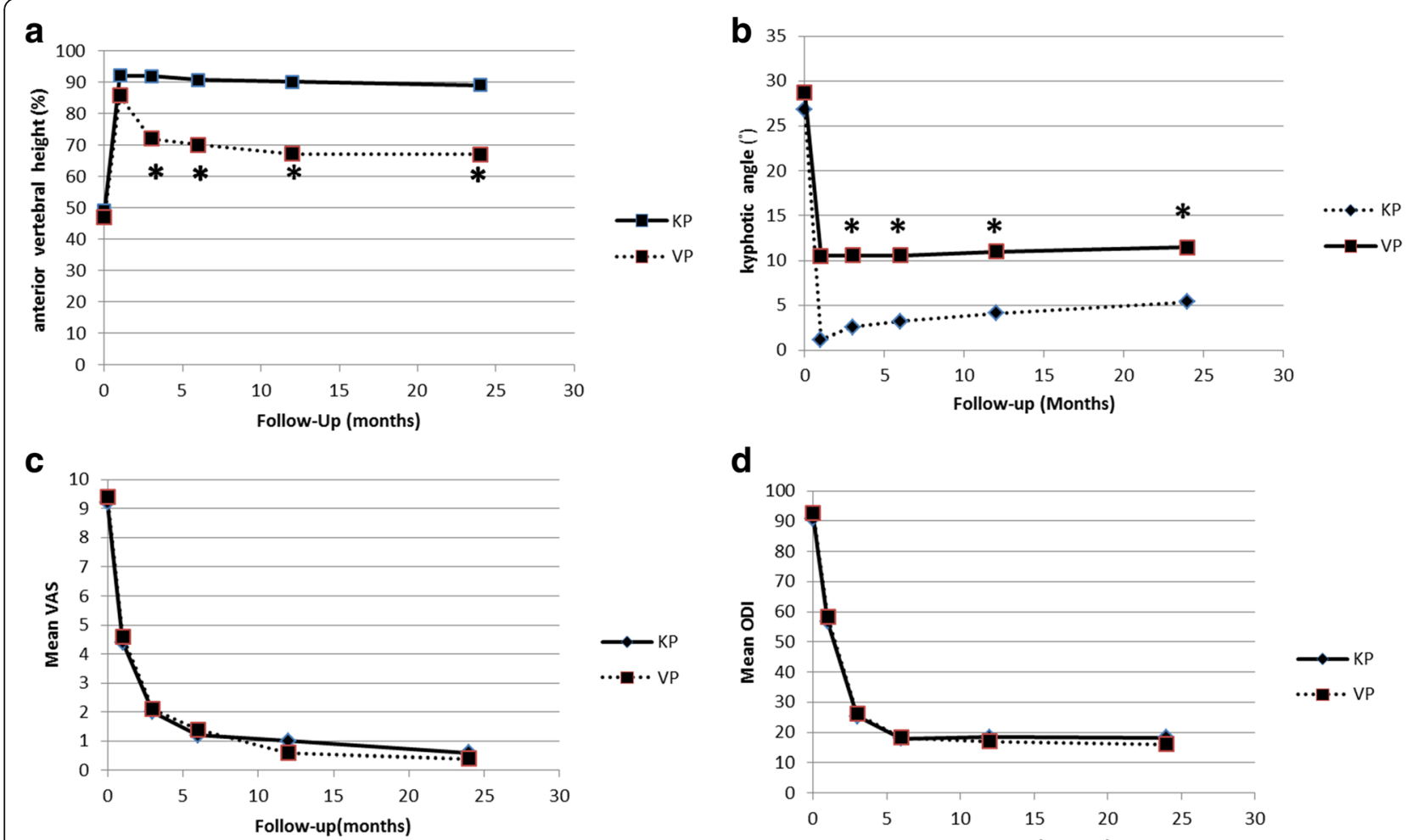

d
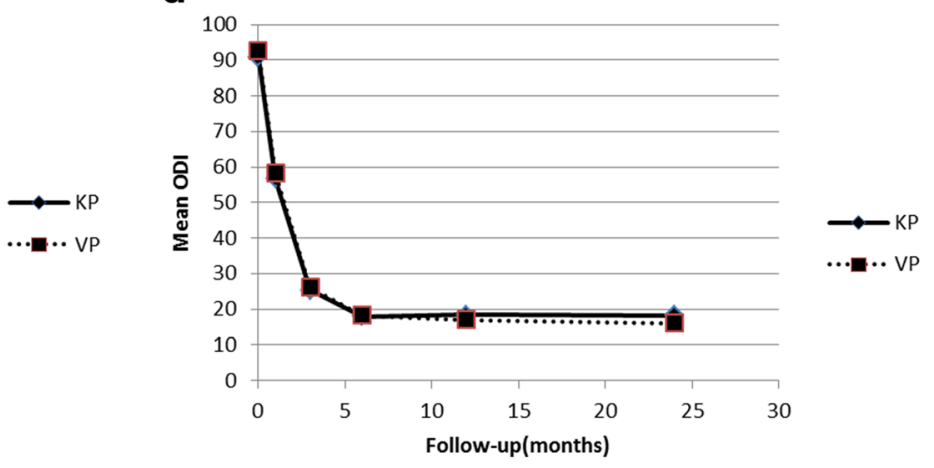

Fig. 5 Comparisons of the kyphoplasty and vertebroplasty in anterior vertebral height (a), kyphotic angle (b), mean VAS (c) and ODI (d) at baseline and follow-up. Group calculated means and 95\% confidence intervals are shown in panels A, B, C and D. In panels A and B, the treatment $p$ value refers to the average treatment effect difference $(*, p<0.05)$ at $3,6,12$, and 24 months follow-up. In panels $C$ and $D$, no clinical treatment effect difference was found at pre-operative and post-operative follow-up

present study, posterior screw fixation combined with kyphoplasty for anterior support produced significantly better kyphosis angle correction and better vertebral body height, as shown during the 24-month follow-up. Using posterior distraction, reduction of fractured vertebrae is improved indirectly by ligamentotaxis but distraction force also increases kyphotic angle. The distraction force applied in the kyphoplasty patients may be lower in the vertebroplasty patients, and thus postoperative lordotic angle may be better in the kyphoplasty
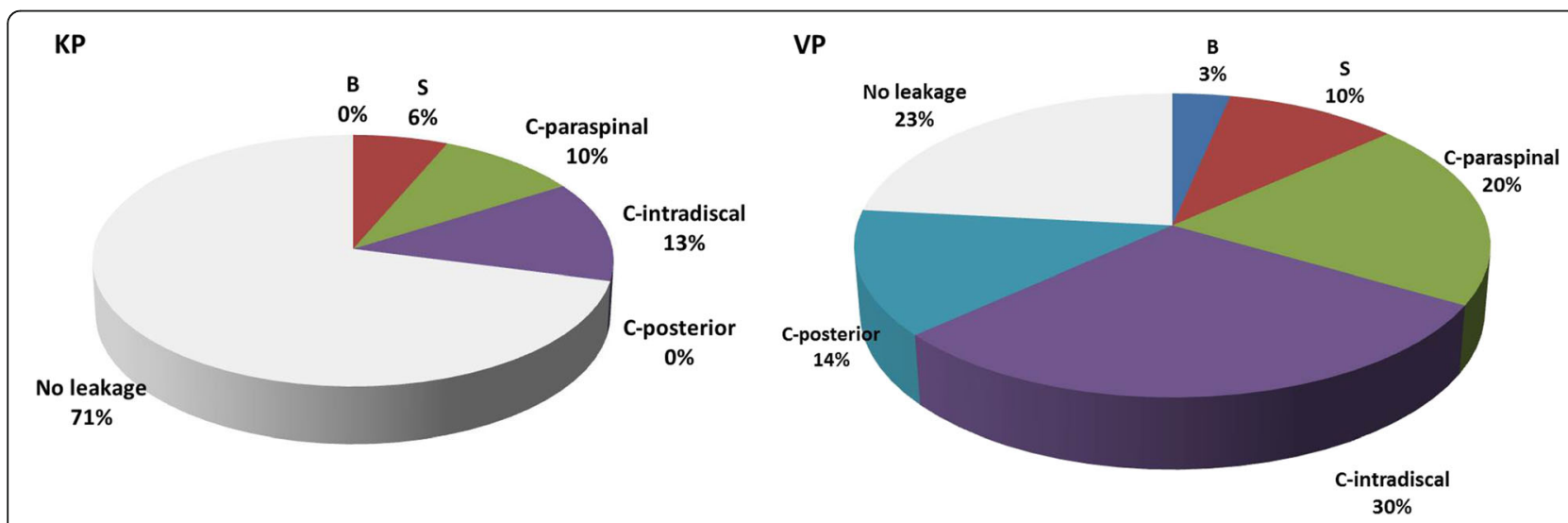

Fig. 6 Comparisons of cement leakage between the kyphoplasty and vertebroplasty groups. Leakages of cement were classified into three different types [22]: type B, through the basivertebral vein; type S, through the segmental vein; and type C, through a cortical defect including three patterns in C-type leakage (i.e., paraspinal, intradiscal, and posterior). Kyphoplasty resulted in considerably less cement extravasation (29\%) than vertebroplasty (77\%). In our series, leakage into the spinal canal (C-posterior type leakage) is significant in the vertebroplasty group (14\% in the vertebroplasty group to $0 \%$ in the kyphoplasty group) 
group. The reported kyphotic angle correction with transpedicular bone grafting and short pedicle fixation techniques ranges from $64 \%$ to $105 \%$ [18, 30-33]. The average corrections of $92 \%$ in the kyphoplasty group and $85.6 \%$ in vertebroplasty group are within the previous reported range. The average loss of correction after posterior short segment instrumentation plus transpedicular augmentation with biodegradable bone cement is not significantly different from that following traditional anterior and posterior spinal operations [18, 30, 34], with the loss of correction ranging from $1^{\circ}$ to $4.2^{\circ}$.

Posterior instrumentation is speculated to fail due to the large bone defect created inside the fractured vertebra after indirect height restoration through distraction and ligamentotaxis force applied during surgery [35]. Because the majority of patients with burst fractures in our series were aged between 29 and 48 years, the use of a more biocompatible bone cements (e.g.,calcium phosphate and hydroxyapatite) is preferred [30, 36, 37]. Self-hardening calcium sulfate/phosphate bone cements have been developed as alternatives to avoid long-term side effects of PMMA [38-40] because of the biocompatibility, no local heat or toxic effect on surrounding bone tissues [41, 42] and can stimulate bone formation at the bone-cement interface [43]. Korovessis P. [44] reported an improvement of kyphotic angle from preoperative $16^{\circ}$ to postoperative $1^{\circ}$ at final follow-up and the AVH ratio from 0.6 to 0.9 in 29 thoracolumbar burst fracture patients using kyphoplasty with calcium phosphate cement and pedicle screws instrumentation and reported a similar result in 18 thoracolumbar burst fracture patients [45] using balloon kyphoplasty with calcium phosphate cement combined with posterior short segmental fixation. In both of their study, they didn't use vertebroplasty as a control group which is difficult to make a conclusion that the reduction using balloon at the site of the fractured vertebra is better than the indirect reduction by means of distraction provided only by instrumentation. We also doubt this similar data $[44,45]$ because of the distraction force applied in open surgery should be larger than minimal invasive method so that radiological result in open surgery should be better.

The reason why significant improvements were noted in kyphotic angle and AVH at post-operative one month, but decreased in the 24-month follow-up in our study, because of the calcium sulfate/phosphate cement was partial resorption.

In this study, the volume injected in the kyphoplasty group was significantly higher than that in the vertebroplasty group $\left(12 \pm 2.5 \mathrm{~cm}^{3}\right.$ vs. $\left.6.5 \pm 1.5 \mathrm{~cm}^{3}, p<0.01\right)$ because the void space in fractured vertebrae was created by balloon kyphoplasty, and thus, the vertebral height and kyphotic angle will be better and maintained in the 24-month follow-up in the kyphoplasty group.
According to the previous studies, balloon assisted kyphoplasty results in considerably less cement extravasation, compared to vertebroplasty [46-48]. In a systematic review of clinical studies, the rate of cement leakage was $9 \%$ in kyphoplasty groups and $41 \%$ in vertebroplasty groups [49]. In a meta-analysis study, cement extravasation were observed in $7 \%$ of patients after kyphoplasty, but in $20 \%$ of patients after vertebroplasty [50]. In the present study, $29 \%$ of the kyphoplasty group had cement leakage, compared to $77 \%$ in the vertebroplasty group (Fig. 6). The higher leakage rate may be due to acute burst fracture in young patients instead of osteoporotic compression in older patients. The lower rate of cement leakage in the kyphoplasty group proved the fact that injection of high-viscosity cement at low pressure into a created cavity is a significant improvement over the injection of low-viscosity cement at high pressure into an unreduced fractured vertebra (Fig. 7) [19, 29, 49]. In our series, leakage into the spinal canal was significant in the vertebroplasty group ( $16 \%$ in the vertebroplasty group to $0 \%$ in the kyphoplasty group), indicating that kyphoplasty is a considerably safe procedure in the treatment of thoracolumbar burst fractures. Only one implant failure (3.3\%), which required further surgical intervention, was found in the vertebroplasty group.

In our series, a larger amount of cement was injected into the vertebrae of the kyphoplasty group; this group exhibited better eventual stability than the vertebroplasty group. The authors believe that the reduction with additional balloon at the fractured site is better than the indirect reduction through distraction force provided by posterior instrumentation. Additional balloon kyphoplasty is safe and effective for acute thoracolumbar burst fracture.

There are several limitations in this study. 1) This is a retrospective study and mean follow-up was 29 months. The long-term effectiveness of this technique still needs

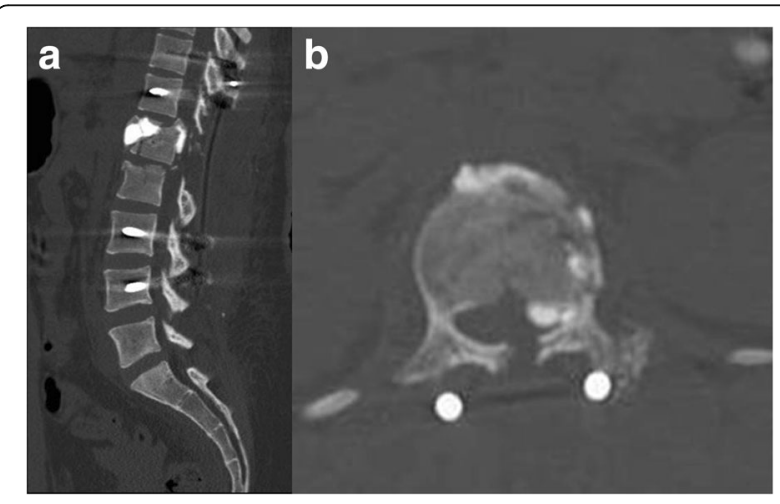

Fig. 7 Cement leakage into the spinal canal after vertebroplasty. Vertebroplasty without balloon inflation causes cement leakage through the cortical disruption as detected on postoperative computed tomography scanning $(\mathbf{a}, \mathbf{b})$ 
to be evaluated. 2) The surgical indication is different in kyphoplasty group and vertebroplasty group. 3) The numbers of the patients in both groups were limited.

\section{Conclusions}

Balloon kyphoplasty and vertebroplasty with injection of calcium sulfate/phosphate cement combined with posterior fixation for acute thoracolumbar burst fractures both provided immediate stability and reduction of posttraumatic segmental kyphosis. In addition, the use of additional balloon kyphoplasty led to better reduction of fractured vertebrae, less cement leakage, and better stability than in patients who only received vertebroplasty.

\section{Acknowledgements}

We thank the Department of Orthopaedic Surgery for their contribution to the study.

\section{Funding}

This work was supported by Chang Gung Memorial Hospital (grant No. CMRPG3F2051).

\section{Availability of data and materials}

The data that support the findings of this study are available from Chang Gung Memorial Hospital but restrictions apply to the availability of these data, which were used under license for the current study, and so are not publicly available. Data are however available from the authors upon reasonable request and with permission of Chang Gung Memorial Hospital.

\section{Authors' contributions}

P-JT, K-FF and M-KH participated in the study design, in collecting the data, the statistically analyses and drafting of the manuscript. L-HC, C-CN, P-LL, W-JC, T-TT and C-WY participated in the study design. M-KH advised and assisted drafting of the manuscript. All authors read and approved the final manuscript.

\section{Ethics approval and consent to participate}

The Chang Gung Medical Foundation Institutional Review Board approved this study (103-3387B) and waived the requirement for informed consent due to the retrospective nature of the study.

\section{Consent for publication}

Not applicable.

\section{Competing interests}

$\Pi T-T$ is a member of the Editorial Board of BMC Musculoskeletal Disorders. The remaining authors have no competing interests.

\section{Publisher's Note}

Springer Nature remains neutral with regard to jurisdictional claims in published maps and institutional affiliations.

\section{Author details}

'Department of Orthopedic Surgery, Chang Gung Memorial Hospital and Chang Gung University, Taoyuan, Taiwan. 'Bone and Joint Research Center, Chang Gung Memorial Hospital, Linkou, Taiwan. ${ }^{3}$ 5, Fu-Hsin Street, Kweishan Shiang, Taoyuan ,333, Linkou, Taiwan.

Received: 12 January 2017 Accepted: 5 September 2017

Published online: 11 September 2017

\section{Reference}

1. Benson DR, Burkus JK, Montesano PX, Sutherland TB, McLain RF. Unstable thoracolumbar and lumbar burst fractures treated with the $\mathrm{AO}$ fixateu interne. J Spinal Disord. 1992;5:335-43.

2. Patel AA, Dailey A, Brodke DS, Daubs M, Harrop J, Whang PG, Vaccaro AR Spine trauma study G: Thoracolumbar spine trauma classification: the
Thoracolumbar injury classification and severity score system and case examples. J Neurosurg Spine. 2009;10:201-6.

3. Hitchon PW, Abode-lyamah K, Dahdaleh NS, Shaffrey C, Noeller J, He W, Moritani T. Nonoperative Management in Neurologically Intact Thoracolumbar Burst Fractures: clinical and radiographic outcomes. Spine (Phila Pa 1976). 2016:41:483-9.

4. Mermelstein LE, McLain RF, Yerby SA. Reinforcement of thoracolumbar burst fractures with calcium phosphate cement. A biomechanical study. Spine (Phila Pa 1976). 1998;23:664-70.

5. Kramer DL, Rodgers WB, Mansfield FL. Transpedicular instrumentation and short-segment fusion of thoracolumbar fractures: a prospective study using a single instrumentation system. J Orthop Trauma. 1995;9:499-506.

6. Wu XT, Jiang XJ, Zhang SD, Yang HL. Biomechanical evaluation of vertebroplasty using calcium sulfate cement for thoracolumbar burst fractures. Chin J Traumatol. 2007:10:327-33.

7. Yang $\mathrm{H}$, Zou J. Filling materials used in kyphoplasty and vertebroplasty for vertebral compression fracture: a literature review. Artif Cells Blood Substit Immobil Biotechnol. 2011;39:87-91.

8. Zaryanov AV, Park DK, Khalil JG, Baker KC, Fischgrund JS. Cement augmentation in vertebral burst fractures. Neurosurg Focus. 2014;37:E5.

9. Arrington ED, Smith WJ, Chambers HG, Bucknell AL, Davino NA Complications of iliac crest bone graft harvesting. Clin Orthop Relat Res. 1996:329:300-9.

10. Liao JC, Fan KF, Keorochana G, Chen WJ, Chen LH. Transpedicular grafting after short-segment pedicle instrumentation for thoracolumbar burst fracture: calcium sulfate cement versus autogenous iliac bone graft. Spine (Phila Pa 1976). 2010;35:1482-8.

11. Deramond H, Wright NT, Belkoff SM. Temperature elevation caused by bone cement polymerization during vertebroplasty. Bone. 1999;25:17-21.

12. Togawa D, Kovacic JJ, Bauer TW, Reinhardt MK, Brodke DS, Lieberman IH. Radiographic and histologic findings of vertebral augmentation using polymethylmethacrylate in the primate spine: percutaneous vertebroplasty versus kyphoplasty. Spine (Phila Pa 1976). 2006;31:E4-10.

13. Kasperk C, Hillmeier J, Noldge G, Grafe IA, Dafonseca K, Raupp D, Bardenheuer H, Libicher M, Liegibel UM, Sommer U, et al. Treatment of painful vertebral fractures by kyphoplasty in patients with primary osteoporosis: a prospective nonrandomized controlled study. J Bone Miner Res. 2005;20:604-12

14. Molloy S, Sewell MD, Platinum J, Patel A, Selvadurai S, Hargunani R, Kyriakou C. Is balloon kyphoplasty safe and effective for cancer-related vertebral compression fractures with posterior vertebral body wall defects? J Surg Oncol. 2016;113:835-42.

15. Boonen S, Van Meirhaeghe J, Bastian L, Cummings SR, Ranstam J, Tillman JB, Eastell R, Talmadge K, Wardlaw D. Balloon kyphoplasty for the treatment of acute vertebral compression fractures: 2-year results from a randomized trial. J Bone Miner Res. 2011;26:1627-37.

16. Wood KB, Li W, Lebl DR, Ploumis A. Management of thoracolumbar spine fractures. Spine J. 2014;14:145-64

17. American Spinal Injury Association/International Medical Society of Paraplegia. International standards for neurological and functional classification of spinal cord injury-revised 2000. Chicago: ASIA; 2002.

18. Korovessis P, Baikousis A, Zacharatos S, Petsinis G, Koureas G, Iliopoulos P. Combined anterior plus posterior stabilization versus posterior shortsegment instrumentation and fusion for mid-lumbar (L2-L4) burst fractures. Spine (Phila Pa 1976). 2006:31:859-68

19. Yu CW, Hsieh MK, Chen LH, Niu CC, Fu TS, Lai PL, Chen WJ, Chen WC, Lu ML. Percutaneous balloon kyphoplasty for the treatment of vertebral compression fractures. BMC Surg. 2014;14:3

20. Kotnis NA, Parasu N, Finlay K, Jurriaans E, Ghert M. Chronology of the radiographic appearances of the calcium sulphate-calcium phosphate synthetic bone graft composite following resection of bone tumours-a preliminary study of the normal post-operative appearances. Skelet Radiol. 2011;40:563-70

21. Christensen FB, Laursen M, Gelineck J, Eiskjaer SP, Thomsen K, Bunger CE. Interobserver and intraobserver agreement of radiograph interpretation with and without pedicle screw implants: the need for a detailed classification system in posterolateral spinal fusion. Spine (Phila Pa 1976). 2001;26:538-43.

22. Yeom JS, Kim WJ, Choy WS, Lee CK, Chang BS, Kang JW. Leakage of cement in percutaneous transpedicular vertebroplasty for painful osteoporotic compression fractures. J Bone Joint Surg Br. 2003;85:83-9. 
23. McLain RF, Sparling E, Benson DR. Early failure of short-segment pedicle instrumentation for thoracolumbar fractures. A preliminary report. J Bone Joint Surg Am. 1993;75:162-7.

24. Olerud S, Karlstrom G, Sjostrom L. Transpedicular fixation of thoracolumbar vertebral fractures. Clin Orthop Relat Res. 1988;227:44-51.

25. Ebelke DK, Asher MA, Neff JR, Kraker DP. Survivorship analysis of VSP spine instrumentation in the treatment of thoracolumbar and lumbar burst fractures. Spine (Phila Pa 1976). 1991;16(Suppl 8):428-32.

26. Galibert $P$, Deramond $H$, Rosat $P$, Le Gars D. Preliminary note on the treatment of vertebral angioma by percutaneous acrylic vertebroplasty. Neurochirurgie. 1987;33:166-8.

27. Kroon F, Staples M, Ebeling PR, Wark JD, Osborne RH, Mitchell PJ, Wriedt CH, Buchbinder R. Two-year results of a randomized placebo-controlled trial of vertebroplasty for acute osteoporotic vertebral fractures. J Bone Miner Res. 2014:29:1346-55.

28. Coumans JV, Reinhardt MK, Lieberman $\mathbb{H}$. Kyphoplasty for vertebral compression fractures: 1-year clinical outcomes from a prospective study. J Neurosurg. 2003;99:44-50.

29. Heini PF, Orler R. Kyphoplasty for treatment of osteoporotic vertebral fractures. Eur Spine J. 2004;13:184-92.

30. Toyone T, Tanaka T, Kato D, Kaneyama R, Otsuka M. The treatment of acute thoracolumbar burst fractures with transpedicular intracorporeal hydroxyapatite grafting following indirect reduction and pedicle screw fixation: a prospective study. Spine (Phila Pa 1976). 2006;31:E208-14.

31. Shen WJ, LiU TJ, Shen YS. Nonoperative treatment versus posterior fixation for thoracolumbar junction burst fractures without neurologic deficit. Spine (Phila Pa 1976). 2001;26:1038-45.

32. Li KC, Li AF, Hsieh CH, Chen HH. Transpedicle body augmenter in painful osteoporotic compression fractures. Eur Spine J. 2007;16:589-98.

33. Li KC, Hsieh CH, Lee CY, Chen TH. Transpedicle body augmenter: a further step in treating burst fractures. Clin Orthop Relat Res. 2005;436:119-25.

34. McDonough PW, Davis R, Tribus C, Zdeblick TA. The management of acute thoracolumbar burst fractures with anterior corpectomy and Z-plate fixation. Spine (Phila Pa 1976). 2004;29:1901-9.

35. Daniaux H. Transpedicular repositioning and spongioplasty in fractures of the vertebral bodies of the lower thoracic and lumbar spine. Unfallchirurg. 1986;89:197-213.

36. Gelb H, Schumacher HR, Cuckler J, Ducheyne P, Baker DG. In vivo inflammatory response to polymethylmethacrylate particulate debris: effect of size, morphology, and surface area. J Orthop Res. 1994;12:83-92.

37. San Millan Ruiz D, Burkhardt K, Jean B, Muster M, Martin JB, Bouvier J, Fase $\mathrm{JH}$, Rufenacht DA, Kurt AM. Pathology findings with acrylic implants. Bone. 1999;25(Suppl 2):85-90

38. Lim TH, Brebach GT, Renner SM, Kim WJ, Kim JG, Lee RE, Andersson GB, An HS. Biomechanical evaluation of an injectable calcium phosphate cement for vertebroplasty. Spine (Phila Pa 1976). 2002;27:1297-302.

39. Tomita S, Molloy S, Jasper LE, Abe M, Belkoff SM. Biomechanical comparison of kyphoplasty with different bone cements. Spine (Phila Pa 1976). 2004;29:1203-7.

40. Cho DY, Lee WY, Sheu PC. Treatment of thoracolumbar burst fractures with polymethyl methacrylate vertebroplasty and short-segment pedicle screw fixation. Neurosurgery. 2003;53:1354-60.

41. Bai B, Jazrawi LM, Kummer FJ, Spivak JM. The use of an injectable, biodegradable calcium phosphate bone substitute for the prophylactic augmentation of osteoporotic vertebrae and the management of vertebral compression fractures. Spine (Phila Pa 1976). 1999;24:1521-6.

42. Chow LC, Takagi S, Constantino PD, et al. Self-setting calcium phosphate cements. Mat Res Soc Symp Proc. 1991;179:1-24.

43. LeGeros RZ. Properties of osteoconductive biomaterials: calcium phosphates. Clin Orthop Relat Res. 2002;395:81-98.

44. Korovessis P, Repantis T, Petsinis G, Iliopoulos P, Hadjipavlou A. Direct reduction of thoracolumbar burst fractures by means of balloon kyphoplasty with calcium phosphate and stabilization with pedicle-screw instrumentation and fusion. Spine (Phila Pa 1976). 2008:33:E100-8.

45. Korovessis P, Hadjipavlou A, Repantis T. Minimal invasive short posterior instrumentation plus balloon kyphoplasty with calcium phosphate for burst and severe compression lumbar fractures. Spine (Phila Pa 1976). 2008;33:658-67.

46. Garfin SR, Yuan HA, Reiley MA. New technologies in spine: kyphoplasty and vertebroplasty for the treatment of painful osteoporotic compression fractures. Spine (Phila Pa 1976). 2001;26:1511-5.
47. Ledlie JT, Renfro MB. Kyphoplasty treatment of vertebral fractures: 2-year outcomes show sustained benefits. Spine (Phila Pa 1976). 2006;31:57-64.

48. Lieberman $\mathbf{I H}$, Dudeney S, Reinhardt MK, Bell G. Initial outcome and efficacy of "kyphoplasty" in the treatment of painful osteoporotic vertebral compression fractures. Spine (Phila Pa 1976). 2001;26:1631-8.

49. Hulme PA, Krebs J, Ferguson SJ, Berlemann U. Vertebroplasty and kyphoplasty: a systematic review of 69 clinical studies. Spine (Phila Pa 1976). 2006;31:1983-2001.

50. Eck JC, Nachtigall D, Humphreys SC, Hodges SD. Comparison of vertebroplasty and balloon kyphoplasty for treatment of vertebral compression fractures: a meta-analysis of the literature. Spine J. 2008;8:488-97.

\section{Submit your next manuscript to BioMed Central and we will help you at every step:}

- We accept pre-submission inquiries

- Our selector tool helps you to find the most relevant journal

- We provide round the clock customer support

- Convenient online submission

- Thorough peer review

- Inclusion in PubMed and all major indexing services

- Maximum visibility for your research

Submit your manuscript at www.biomedcentral.com/submit
Biomed Central 